\title{
O PERCURSO HISTÓRICO DAS POLÍTICAS PÚBLICAS DE ATENÇÃO À CRIANÇA E AO ADOLESCENTE NO BRASIL: O PERÍODO DE 1920 A 1979
}

\author{
Márcia Cossetin ${ }^{1}$ \\ Angela Mara de Barros Lara ${ }^{2}$
}

\section{RESUMO}

Este artigo tem como objetivo apresentar o percurso histórico de construção das políticas públicas de atenção à criança e ao adolescente no Brasil no período de 1920 a 1979, às quais denotam o atendimento, denominado, muitas vezes, como educativo, para esse público. Para tanto, realizamos pesquisa documental e bibliográfica e nos apoiamos em autores que pesquisam a temática. No período delimitado são apresentados dois importantes documentos para o atendimento à criança e ao adolescente no Brasil, quais sejam: o Código de Menores de 1927 e o Código de Menores de 1979, legislações em que nos focamos neste artigo. Pudemos apreender, por meio dos estudos realizados, que o atendimento, as práticas e as concepções de repressão e segregação, relativas à infância e à adolescência pobres, de modo geral, foram ocasionadas em decorrência da própria constituição da sociedade de classes. Esta constituição que demanda, principalmente às classes subalternas, um comportamento condizente com a organização do processo de produção.

Palavras-Chave: Criança; Adolescente; Políticas Públicas; Códigos de Menores.

\section{THE HISTORICAL COURSE OF PUBLIC POLICIES AND THE ATTENTION TO CHILDREN AND ADOLESCENTS IN BRAZIL: IN THE PERIOD 1920-1979}

\begin{abstract}
This article aims to present the historical course of the construction of public policies and the attention to children and adolescents in Brazil in the period 1920-1979, which denote the service, called often as education for the public. Therefore, we had performed documentary and bibliographic research and support the authors in researching the topic. In the defined period are presented two important documents for the care of children and adolescents in Brazil, namely: the 1927 Juvenile Code and the 1979 Children's Code, laws which we focused in this article. Were able to get, through studies, the service, the practices and the conceptions of repression and segregation, related to childhood and teenager poor, in general, were caused due to the very existence of class society. This constitution that demand, mainly the subaltern classes with a reasonable behavior with the organization of the production process.
\end{abstract}

Keywords: Child, Teenager, Public Politics, Juvenile codes.

\section{Introdução:}

Neste artigo traremos a gênese do atendimento às crianças e aos adolescentes denominados como infratores no Brasil, considerando que as apresentações do presente para este segmento foram historicamente construídas por meio de avanços e retrocessos, nunca obedecendo a uma linearidade, mas ajustando-se às mudanças necessárias advindas da organização social, refletindo os ajustes, os embates e as contradições inerentes à sociedade de classes. 
Iniciamos nosso estudo na década de 1920, com o Código de Menores de $1927^{3}$ e perpassamos o Código de Menores de 1979. O período delimitado justifica-se pelo fato de que são apresentadas, no início do século XX, no Brasil, as primeiras legislações que tratam da questão da infância e da adolescência, especialmente para os abandonados e os considerados delinquentes e, demarcamos como final do estudo, o período anterior à redemocratização do país no final da década de 70 do século XX, por ter sido instituído, nesse período, um novo Código de Menores.

No Brasil, o processo de institucionalização e de apresentação das primeiras legislações e ações gestadas pelo Estado para o atendimento à infância e à adolescência infratora e pobre passou a ocorrer a partir das primeiras décadas do século XX.

Nesse período, a economia agroexportadora ainda era predominante. A industrialização começava a se formar e havia um movimento da sociedade formada pelo proletariado, que não era de grande número, sendo constituído, praticamente, por imigrantes submetidos à exploração extrema pela burguesia local. Ambos, embora com interesses opostos, cobravam reformas que propiciassem desenvolvimento no processo de industrialização e, consequentemente, no país (Carvalho, 2009).

Dentre as reivindicações, a educação era enfatizada como propulsora do processo de mudanças que eram necessárias para o desenvolvimento. Esta era entendida, conforme Xavier (1990), por meio dos pressupostos educacionais liberais que atendiam tanto aos anseios das classes subalternas quanto das classes médias e da classe dominante. As primeiras buscavam a superação da miséria, ignorando, contudo, suas reais causas; as segundas almejavam ter maior participação nos privilégios e, raras vezes, preocupavam-se com a extinção destes; e a última explorava e alimentava essas ilusões. "Afinal expandir as oportunidades educacionais ou reformar as instituições escolares representava um custo menor do que alterar a distribuição de renda e as relações de poder" (XAVIER, 1990, p. $63)$.

Nesse contexto, surgem discussões também a respeito do atendimento às crianças e aos adolescentes infratores, abandonados e carentes, pois, com a formação de alguns centros urbanos, cresciam os problemas causados por essa parcela da população, considerada como um entrave ao sucesso no processo de desenvolvimento do país.

Com a expansão da educação e com o entendimento de que, por meio desta, poderse-ia recuperar o atraso do Brasil em relação aos outros países, são discutidas também ações que pudessem integrar os sujeitos jovens que perambulavam pelas ruas das cidades. Desse modo, são apresentadas as primeiras legislações que regulamentam o atendimento às crianças e aos adolescentes pobres, infratores, abandonados e delinquentes.

\section{A construção do primeiro Código de Menores (1927): Assistência e Proteção ou Punição aos Pobres}

Em 1920 realiza-se o $1^{\circ}$ Congresso Brasileiro de Proteção à Infância, tornando as discussões mais sistemáticas a respeito da proteção social a este segmento. Desse modo, em 1921, por meio da lei federal orçamentária $n^{\circ} 4.242$, o governo autoriza a organização de políticas de proteção e de assistência ao menor ${ }^{4}$ abandonado e delinquente, associando estratégias de assistência e repressão (Faleiros, 2011).

Passa-se a regulamentar uma separação entre a infância e os menores, o que, na prática, já era bem definida. Conforme expõe Faleiros (2011), o Brasil, historicamente, construiu uma nítida diferenciação entre as políticas que se destinavam aos filhos da classe dominante e às crianças e adolescentes pobres. A primeira classe era atendida pela família e recebia a educação escolar, já os segundos, denominados de menores, a quem se 
destinavam as leis, ficavam sob os cuidados do Estado e, para estes, a educação visava somente à instrumentalização para o trabalho.

Essa caracterização é apontada também nos estudos de Marcílio (1989), ao analisar que

A distinção entre criança rica e a criança pobre ficou bem delineada. A primeira é alvo de atenções e das políticas da família e da educação, com o objetivo de prepará-la para dirigir a sociedade. A segunda, virtualmente inserida nas 'classes perigosas' e estigmatizada como 'menor', deveria ser objeto de controle especial, de educação elementar e profissionalizante, que a preparasse para o mundo do trabalho. Disso cuidaram com atenção os médicos higienistas e os juristas das primeiras décadas deste século (MARCÍlIO, 1989, p. 224).

Em consonância com tal caracterização, em 20 de dezembro de 1923, aprova-se o decreto $\mathrm{n}^{\circ}$ 16.272, que institui o regulamento de assistência e de proteção aos menores abandonados e delinquentes. Este decreto, conforme Rizzini (2011), constituiu o conteúdo básico para a elaboração do Código de Menores de 1927, por meio do decreto nº 17.943-A, de 12 de outubro, que manteve inalteradas as determinações dos sujeitos a quem se destinava a nova lei: as crianças e os adolescentes pobres.

O Estado atuava no sentido de tomar para si a tarefa de educar/corrigir o comportamento de adolescentes e crianças de famílias das classes subalternas da sociedade. Oliveira (1999) assinala que, na década de 1920, concretizam-se ações que demarcam a mudança da simples repressão para a segregação, na medida em que o Estado afasta as crianças e os adolescentes, por meio da internação, dos locais considerados inadequados. Procurava-se prevenir o contágio pelos menores, retirando-os do convívio social para que, então, adolescentes e crianças fossem submetidos

[...] a medidas preventivas e corretivas, que estariam a cargo de instituições públicas. O Código de Menores Mello Matos, de 1927, consolida legalmente esta prática de prevenção ligada ao ideário de periculosidade (OLIVEIRA, 1999, s/p).

O Estado passa a exercer maior controle sobre a população infanto-juvenil e sobre a vida das famílias pobres de modo geral. Além disso, busca maior organização e regulação da vida em sociedade, amparando-se, para isso, na legislação e na ciência médica. A ciência médica tem importante participação como propositora de intervenções e elege a infância pobre como categoria específica para aplicação de seus saberes. Conforme apontam Rizzini e Rizzini (2004) os médicos higienistas tiveram participação significativa na construção e na implantação de um projeto assistencial direcionado às crianças e aos adolescentes pobres, aos menores, usando-se, para isso, de teorias, de conceitos e de saberes técnicos que são empregados até na contemporaneidade para solucionar os problemas relacionados ao segmento infanto-juvenil.

É desse modo que se atende à necessidade da época em que os centros urbanos enfrentavam problemas sociais oriundos do início da organização comercial e industrial. No Brasil, as elites do período exigiam do Estado ações para coibir as ameaças que os menores representavam para o projeto de sociedade que estava em construção. Os médicos, filantropos e educadores buscavam discutir qual o caminho para solucionar os problemas relacionados a esses sujeitos (MIRANDA, 2008).

O Código de Menores do Brasil ${ }^{5}$, que foi chamado Código Mello Mattos ${ }^{6}$, seguia a lógica de intervenção originada pelas situações de pobreza a que estavam expostos os 
abandonados e os denominados de delinquentes. Não previa a instituição de direitos, mas apresentava como base uma orientação preventiva e repressora que visava à punição dos não ajustados ao processo de desenvolvimento empreendido pelo país (MIRANDA, 2008).

De acordo com Faleiros (2011), o Código de Menores de 1927 “[...] incorpora tanto a visão higienista de proteção do meio e do indivíduo, como a visão jurídica repressiva e moralista" (FALEIROS, 2011, p. 47), pois, entre outros fatores, surgiu pelo empenho de médicos que se mostravam preocupados, em conjunto com outros setores, com a questão do desenvolvimento da sociedade.

A concepção higienista previa intervenções propostas pela medicina com o objetivo de sanar doenças; propagava a proteção do indivíduo e da sociedade, por meio do desenvolvimento de bons hábitos de higiene e morais. Não se pode negar que, no contexto histórico do Brasil no período, esta concepção colaborou na prevenção de doenças, no entanto, apreendemos que serviu, também, para justificar a internação de adolescentes e crianças que não se enquadravam no modelo social em construção.

Destacava-se, ainda, o papel relevante desempenhado pelos juristas que buscavam o aparato policial para destinar os tratamentos que consideravam adequados aos chamados delinquentes juvenis. A partir de então, a questão do menor não é objeto apenas da esfera policial; é social, pois além de contar com a atuação jurídica/policial, integra-se à medicina e à educação, conforme aponta Oliveira (1999)

Cabia ao higienista os cuidados com saúde, nutrição e higiene; ao educador, a disciplina e instrução; e ao jurista, conseguir que a lei garantisse essa proteção e assistência. [...] a questão do 'menor' já ultrapassava o campo policial para ser equacionada como política social (OLIVEIRA, 1999, s/p).

Essa integração, alicerçada por meio de medidas jurídicas, tinha por finalidade mais significativa cessar ou prevenir o comportamento perigoso ou inadequado do indivíduo. Objetivava-se, quando se dava ênfase, por exemplo, à personalidade, que era considerada tão importante quanto o crime cometido, a internação para, posteriormente ao tratamento, o sujeito ser reintegrado socialmente por meio de ações educativas e disciplinadoras. A atuação médica mostrava-se tão importante nesse processo que se previa um médico, na especialidade de psiquiatria, para acompanhar os procedimentos em caso de apreensão da criança e do adolescente. As atribuições de sua função, nesse contexto, estavam expostas no Código de Menores, em seu artigo 150, especificando que a este profissional cabia:

I, proceder a todos os exames medicos e observações dos menores levados a juizo, e aos que o juiz determinar;

II, fazer ás pessoas das famílias dos menores as visitas medicas necessarias para as investigações dos antecedentes hereditarios e pessoaes destes;

III, desempenhar o serviço medico do Abrigo annexo ao juizo de menores (BRASIL, 1927, s/p).

O Código anunciava-se como instrumento de assistência e de proteção com o objetivo de educar, no entanto, em seu artigo $1^{\circ}$, revelava quem seriam os destinatários das determinações nele expressas: não todas as crianças e adolescentes, mas: "O menor, de um ou outro sexo, abandonado ${ }^{7}$ ou delinqüente, que tiver menos de 18 annos de idade, será submettido pela autoridade competente às medidas de assistencia e protecção contidas 
neste Código" (BRASIL, 1927, s/p), ou seja, a infância pobre, inclusos os denominados de vadios, de libertinos e os mendigos ${ }^{8}$.

Além dos chamados delinquentes, aos abandonados, aos vadios, aos mendigos e aos libertinos também estava prevista a possibilidade de internação após uma avaliação social que incluía aspectos morais e econômicos dos pais ou responsáveis. Se ficasse provado, por meio da avaliação, que eles não poderiam cuidar das crianças, elas seriam encaminhadas para internação em hospitais, em institutos de educação, em escolas de preservação ou de reforma (MOURA, 2005).

O menor de 14 anos não era submetido, de acordo com o artigo 68 do Código, a processo penal, contudo, passaria por avaliações para verificação de seu estado mental, físico e moral, que definiria a sua consciência ou não na infração praticada. A partir de então é que a autoridade judiciária definiria o que poderia ser aplicado em cada caso: se o jovem fosse considerado em estado de "[...] alienação ou deficiencia mental, fôr apileptico, surdo-mudo, cego, ou por seu estado de saude precisar de cuidados especiaes, a autoridade ordenará seja elle submettido no tratamento apropriado" (BRASIL, 1927, s/p); no caso de ser abandonado ou pervertido ou se estivesse em perigo de ser, "[...] a autoridade competente proverá a sua collocação em asylo, casa de educação, escola de preservação ou confiará a pessoa idonea por todo o tempo necessario á sua educação comtando que não ultrapasse a idade de 21 annos" (BRASIL, 1927, s/p). Não se aplicando em nenhuma das categorias estabelecidas, o sujeito poderia ser entregue aos responsáveis. Configura-se, assim, a punição preventiva, pois, se a autoridade entendesse que havia possibilidade de o menor vir a infringir a lei no futuro, poder-se-ia aplicar uma medida de reclusão para prevenir a infração.

No caso dos maiores de 14 anos e dos menores de 18 anos, previa-se um processo especial, composto da avaliação das condições sociais, econômicas, físicas e mentais do jovem e de sua família. Após a análise, o juiz poderia decretar a internação em escola de reforma com duração de um a cinco anos, caso não fosse considerado abandonado. Sendo abandonado, a internação poderia ser de três a sete anos, sendo reavaliada a, no máximo, cada dois anos pelo juiz. Moura (2005) aponta que para muitos adolescentes, isso significava permanecer recolhido até a idade adulta. Acreditava-se que, com essas medidas, o crime seria coibido e a criminalidade reduzida ao se afastar do cenário os problemas sociais gerados com o fim da escravatura e com a entrada dos imigrantes no país.

O Estado, ao atuar como repressor dos comportamentos entendidos como perigosos, utilizava-se da segregação dos jovens infratores e abandonados, inserindo os últimos no conceito de periculosidade. A identificação dos jovens e das crianças pobres como potencialmente criminosas e abandonadas reafirma o processo de prevenção geral que direcionava as políticas do Estado para a tutela e para a educação. Para tanto, eram necessárias escolas e internatos (MOURA, 2005).

As práticas educativas efetivamente implantadas nos internatos direcionavam-se, exclusivamente, para o trabalho, que era, geralmente, o trabalho manual ou braçal. De acordo com estudos de Colombo (2006), é preciso separar o discurso posto nos documentos do que realmente ocorria: anunciava-se proteção, mas não havia vagas e infraestrutura; preconizava-se a educação, mas, quando havia vagas, as práticas limitavamse ao trabalho, não oferecendo nem mesmo o ensino primário para inserção no mercado trabalho.

Apesar disso, é inegável que o referido Código significou certo avanço, na medida em que estabeleceu a proibição do trabalho aos menores de 14 anos $^{9}$, jornada de trabalho de 6 horas para os menores de 18 anos e previu a instalação de unidades específicas para o 
atendimento às crianças e aos adolescentes privados de liberdade, separando-os dos adultos. Mas, em contrapartida, conforme assinala Rizzini (2011), não há registro de inspeções para averiguar o cumprimento do Código quanto ao trabalho infantil. Já em relação à separação dos adultos no cumprimento da internação, o artigo 86 enunciava: "Nenhum menor de 18 annos, preso por qualquer motivo ou apprechendido, será recolhido a prisão commum" (BRASIL, 1927, s/p). Pode-se ler na sequência do próprio artigo, parágrafo $3^{\circ}$, o estabelecimento de exceção em contrário:

Em caso, porén, de absoluta necessidade, pela impossibilidade material de encontrar quem possa acolher provisoriamente o menor, póde este ser guardado preventivamente em algum compartimento da prisão commum, separado, entretanto, dos presos adultos (BRASIL, 1927, s/p).

Ratificando o procedimento, no artigo 87 declara-se:

Em falta de estabelecimentos apropriados á execução do regimen creado por este Codigo, os menores de 14 a 18 annos sentenciados a internação em escola de reforma serão recolhidos a prisões comuns, porém, separados dos condemnados maiores, e sujeitos a regime adequado; disciplinar, educativo, em vez de penitenciário (BRASIL, 1927, s/p).

Logo, apresenta-se a possibilidade de encaminhar os adolescentes para prisões comuns no caso de faltarem vagas em instituição própria para atender ao regime disciplinar e educativo indicado na lei, configurando-se como espaço de recolhimento e segregação. Além disso, nas unidades exclusivas para menores, desconsideravam-se as particularidades de cada sujeito, recolhendo em um mesmo local todas as crianças e adolescentes, independente da especificidade de cada caso, colocando junto os abandonados, os agressores, os homicidas entre outros.

Concordamos com Rizzini (2011), quando analisa que o Código veio dar sustentação para o objetivo de manutenção da ordem, na perspectiva de que "[...] ao zelar pela infância abandonada e criminosa, prometia extirpar o mal pela raiz, livrando a nação de elementos vadios, desordeiros, que em nada contribuíam para o progresso do país" (RIZZINI, 2011, p. 139). Associava-se justiça e assistência na promessa de atuar no processo de construção da sociedade brasileira civilizada, em direção à consolidação do desenvolvimento nacional.

No entanto, o modelo apresentado pelo Estado popularizou-se com várias publicações na imprensa do Rio de Janeiro e com a crescente demanda de internações, emergindo como uma alternativa de "cuidados e educação" para os pobres (RIZZINI; RIZZINI, 2004, p. 30). Dessa forma, muitos pais em situação de pobreza solicitavam a internação dos filhos.

Ainda que a Revolução de 1930 representasse mudanças na política do país, não significou modificações expressivas no trato com as crianças e com os adolescentes, sujeitos do Código de Menores de 1927. Em relação à educação dispensada às crianças e aos adolescentes pouco se alterou; manteve-se a questão inserida no âmbito do judiciário e da assistência e não como segmento que necessitava ser observado na instituição de direitos.

Se analisarmos o período entre as décadas de 1930 e 1970, podemos perceber que o Brasil caracterizou-se por apresentar a instituição de políticas sociais que focalizavam determinados públicos. Esse período, nos países europeus, denominou-se de Estado de Bem Estar Social. Contudo, no Brasil, não houve Estado de Bem Estar Social, mas 
políticas desenvolvimentistas que visavam sustentar a estrutura econômica, política e social. Como assinala Vieira (2001) nos países periféricos do capitalismo, como é o caso brasileiro, o que ocorreu foi uma "[...] intervenção estatal no domínio econômico e social, no sentido de resguardar e garantir alguns serviços sociais" (VIEIRA, 2001, p. 20) ${ }^{10}$.

De tal modo, ainda na vigência desse Código, seguindo a mesma perspectiva no trato com a infância e a adolescência pobres, no ano de 1940, durante a Ditadura Civil Militar de Getúlio Vargas, foi criado o Serviço de Assistência ao Menor - SAM - instituído pelo decreto-lei $\mathrm{n}^{\mathrm{o}} 3.799$, de 05 de novembro de $1941^{11}$. O SAM era um órgão ligado ao Ministério da Justiça, responsável por fiscalizar e organizar o atendimento em regime de internação dispensado tanto aos autores de atos infracionais quanto aos abandonados e carentes. Inicia-se um processo de centralização, pois, de acordo com Rizzini e Rizzini (2004), na ditadura implantada por Getúlio Vargas, as intervenções sobre a infância tornam-se uma questão de segurança nacional.

No processo de transição, em que o atendimento aos adolescentes autores de ações infracionais passa a ser responsabilidade do SAM, Rizzini e Rizzini (2004) assinalam que o

[...] sistema é avaliado, repetem-se as incongruências, propõem-se mudanças. Instalado o SAM, o esforço de identificar os problemas e carências das instituições volta-se para o menor e para sua família. As dificuldades de viabilizar as propostas educacionais do Serviço são depositadas no assistido, considerado 'incapaz', 'sub-normal de inteligência e de afetividade', e sua 'agressividade', superestimada (RIZZINI; RIZZINI, 2004, p. 33, grifo das autoras).

O que se observa no período de coordenação do SAM são as mesmas práticas e tratamentos às crianças e aos adolescentes, categorizando-os, responsabilizando-os e atendendo-os por meio da segregação social. É importante considerarmos, conforme especifica Faleiros (2011), que esse trato delineou e influenciou as propostas e encaminhamentos posteriores.

A política da infância, denominada 'política do menor', articulando repressão, assistência e defesa da raça, se torna uma questão nacional, e, nos moldes em que foi estruturada, vai ter uma longa duração e uma profunda influência nas trajetórias das crianças e adolescentes pobres desse país (FALEIROS, 2011, p. 57).

Após dez anos de sua implantação, na década de 1950, começaram a surgir diversas denúncias direcionadas às instituições coordenadas pelo SAM. Vinham a público acusações de maus tratos que incluíam agressões físicas, violência sexual, falta de higiene, alimentação insuficiente e inadequada, superlotação de unidades, entre outros. Sobre isso, Rizzini (2011) aponta que existiam poucos educandários considerados como modelos, mas predominavam no SAM os depósitos de menores, onde as práticas mais comuns eram as de maus tratos, ensino deficiente e, ainda, exploração dos internos.

Com o golpe militar de 1964 e a repercussão das irregularidades presentes no órgão, o SAM é extinto e é criada a Fundação Nacional do Bem-Estar do Menor FUNABEM - por meio da lei 4.513, de $1^{\circ}$ de dezembro de 1964, e a Política Nacional de Bem-Estar do Menor - PNBEM. A FUNABEM passa a articular as ações nacionais para os chamados menores e propõe, ainda, com incentivo do Governo Federal, as Fundações Estaduais de Bem Estar do Menor - FEBEMs -, executoras do atendimento aos adolescentes privados de liberdade, e que seriam instaladas em cada estado da Federação. 
A FUNABEM, segundo Faleiros (2011), celebra acordos entre os organismos estatais e privados e centra-se na "[...] proposição e assinatura de convênios a partir da racionalidade imposta pelos técnicos, além de manter o que foi chamado de centro-piloto, instalado no Rio de Janeiro e que deveria servir de modelo a todo o Brasil" (FALEIROS, 2011, p. 67). Além disso, a FUNABEM propôs a instalação de "[...] Centros de Recepção e Triagem para diagnóstico, dividindo os meninos e as meninas atendidos em carenciados, por um lado, e de conduta anti-social, por outro" (FALEIROS, 2011, p. 67).

Conforme Mota (2008), o Brasil, nesse período, buscava atender aos parâmetros do processo de acumulação e se utilizava, para isso, de estratégias que procuravam realizar a contenção do que poderia ser considerado como uma rebeldia política das classes. Pretendia alcançar uma ordem consentida ${ }^{12}$, estabelecendo algumas mudanças nas políticas sociais e priorizando serviços sociais básicos. Implementados de acordo como o projeto político em andamento, procurava satisfazer à "[...] estratégia de modernização autoritária adotada pelos governos militares" (MOTA, 2008, p. 137, grifos da autora).

Retomando o discurso da segurança nacional, de acordo com Rizzini e Rizzini (2004), instaura-se, a partir de então, uma política anti-SAM, a qual enunciava a valorização da vida familiar e da integração do adolescente na comunidade. E, apesar de propagar a internação como último recurso, não foi o que se efetivou nas ações.

A tentativa de organização das leis e ações voltadas para o atendimento a este segmento, na medida em que continuava a ser concebida com base em um caráter repressivo e assistencialista, que se autodesignava como de assistência e proteção, não conseguia alcançar aos objetivos apresentados nos discursos, nem ao menos instituir proteção e direitos de fato às crianças e aos adolescentes.

Sob o governo de uma nova Ditadura Militar, a repressão a qualquer forma de manifestação que infringisse a ordem nacional intensifica-se de maneira significativa. Dessa forma, o atendimento às crianças e aos adolescentes expressava também esse novo contexto, tendo na reclusão uma linha de ação corriqueira. $\mathrm{O}$ atendimento no interior das unidades reflete esta mesma postura repressiva. Assim, com raras exceções, a FUNABEM e mais especificamente as FEBEMs reproduzem o tratamento desumano dispensado anteriormente pelo extinto SAM.

A partir da década de 1970, com a crise estrutural do capital e a necessidade de sua reestruturação, ocorre a retirada dos escassos investimentos em políticas sociais. O que se vê são investimentos no sentido de contenção e de repressão pela força, características do Estado organizado na/pela Ditadura Militar.

$\mathrm{O}$ contexto reflete-se no atendimento destinado à infância e à adolescência em que a perspectiva de atenção do trabalho oferecido a elas era a da punição e de ajuste aos moldes sociais considerados adequados.

\section{Nova lei e antigas práticas: o Código de Menores de 1979}

Após discussões iniciadas em 1976, em 1979 foi promulgado o novo Código de Menores, lei 6.697, de 10 de outubro de 1979, prevalecendo, mais uma vez, segundo Rizzini (2011), a visão dos juristas. O novo Código foi uma revisão do anterior, seguindo a mesma orientação no que se refere ao assistencialismo, à repressão e à desobrigação, em relação ao estabelecimento de direitos aos sujeitos infanto-juvenis. Continua a apresentarse claramente a caracterização das crianças e dos adolescentes pobres, por meio da situação irregular $^{13}$, mantendo para este público a designação de menores ${ }^{14}$, o que fica claro no texto de seu artigo $2^{\circ}$ : 
Para efeitos deste Código considera-se em situação irregular o menor:

1 - privado de condições essenciais a sua subsistência, saúde e instrução obrigatória, ainda que eventualmente em razão de: a) falta, ação ou omissão, dos pais ou responsável; b) manifesta impossibilidade dos pais ou responsável para provê--las;

11 - vítima de maus tratos ou castigos imoderados impostos pelos pais ou responsáveis;

111 - em perigo moral, devido: a) encontrar-se, de modo habitual, em ambiente contrário aos bons costumes; b) exploração em atividade contrária aos bons costumes;

IV - privado de representação ou assistência legal, pela falta eventual dos pais ou responsável;

$\mathrm{V}$ - com desvio de conduta em virtude de uma grave inadaptação familiar ou comunitária;

Vl - autor de infração penal (BRASIL, 1979, s/p).

Desse modo, as crianças e os adolescentes pobres configuram-se em estado de situação irregular, fora da situação de normalidade. Seguindo a mesma concepção do Código de Menores de 1927, mantinha-se a separação nítida entre infância e os denominados de menores. A criança e o adolescente só adquiriam visibilidade e notoriedade social ao estarem à margem da situação estabelecida como normalidade, configurando-se, por parte do Estado, a mesma estratégia de controle e de assistencialismo designada às populações mais carentes.

De acordo com Faleiros (2011), a situação irregular atenderia tanto aos pobres em situação de risco, para quem se desenvolveriam ações assistenciais, quanto aos considerados perigosos ou delinquentes, que expõem a sociedade a riscos. A estes demandariam ações repressivas. O juiz era quem determinava, sustentando suas decisões em pareceres técnicos, o futuro dos dois grupos. Entendemos que a situação de pobreza determinava a irregularidade social.

As políticas propostas pelo Estado para os considerados em situação irregular deveriam propiciar a correção dos desajustados socialmente, assim como prevenir e assistir o menor para que ele não se distanciasse do processo considerado adequado para seu desenvolvimento e comportamento.

Entretanto, conforme já ocorria na vigência do Código de 1927, a responsabilidade pela condição social era atribuída exclusivamente ao sujeito e à sua família, apontando, individualizando e caracterizando as famílias desestruturadas, nas quais poderiam ser gestados os futuros infratores. Para Passeti (1991), o Estado atuava com o objetivo de evitar o "[...] desfecho do circuito da pobreza - práticas anti-sociais - marginalização, alterando-o para pobreza - conduta anti-social - instituição - reintegração" (PASSETI, 1991, p. 159).

O artigo 13 do Código de 1979 anunciava esta reintegração: "Toda medida aplicável ao menor visará, fundamentalmente, à sua integração sócio-familiar" (BRASIL, 1979, s/p). No entanto, questionamos a que reintegração as propostas do Estado estavam fazendo referência, posto que o atendimento, que ainda era realizado por meio da FUNABEM e das FEBEMs, era deficiente e insuficiente, e que a desigualdade social crescia, gerando maior pobreza.

Quanto às medidas que poderiam ser aplicadas pela autoridade judiciária aos chamados menores, o artigo 14 as descreve:

I - advertência; 
II - entrega aos pais ou responsável, ou a pessoa idônea, mediante termo de responsabilidade;

III - colocação em lar substituto;

IV - imposição do regime de liberdade assistida;

$\mathrm{V}$ - colocação em casa de semiliberdade;

VI- internação em estabelecimento educacional, ocupacional, psicopedagógico, hospitalar, psiquiátrico ou outro adequado (BRASIL, 1979, s/p).

Essas medidas poderiam, a critério do juiz, ser cumuladas, ou seja, o adolescente estaria sujeito, por um mesmo crime, a ser condenado ao cumprimento de duas medidas. Contudo, o Código estabelecia a inovação de apresentar a internação somente quando as demais medidas não fossem possíveis de serem aplicadas (BRASIL, 1979, s/p).

O Código de Menores de 1979 mantinha a reavaliação da manutenção ou suspensão da medida no prazo máximo de dois anos. Ao completar 21 anos, o jovem seria avaliado e, se verificada a necessidade da manutenção em regime fechado, seria submetido à lei penal e encaminhado, se fosse o caso, para cumprimento de pena em local indicado para adultos. Esse Código pactuava, ainda, com o encaminhamento dos adolescentes para estabelecimento que aprisionava adultos, não diferindo do Código de 1927. Conforme anunciava o texto do artigo 41 do Código de 1979, o adolescente que apresentasse:

[...] desvio de conduta ou autor de infração penal poderá ser internado em estabelecimento adequado, até que a autoridade judiciária, em despacho fundamentado, determine o desligamento, podendo, conforme a natureza do caso, requisitar parecer técnico do serviço competente e ouvir o Ministério Público.

$\S 1^{\circ} \mathrm{O}$ menor sujeito à medida referida neste artigo será reexaminado periodicamente, com o intervalo máximo de dois anos, para verificação da necessidade de manutenção de medida.

$\S 2^{\circ} \mathrm{Na}$ falta de estabelecimento adequado, a internação do menor poderá ser feita, excepcionalmente, em seção de estabelecimento destinado a maiores, desde que isolada destes e com instalações apropriadas, de modo a garantir absoluta incomunicabilidade.

$\S 3^{\circ}$ Se o menor completar vinte e um anos sem que tenha sido declarada a cessação da medida, passará à jurisdição do Juízo incumbido das Execuções Penais.

$\S 4^{\circ} \mathrm{Na}$ hipótese do parágrafo anterior, o menor será removido para estabelecimento adequado, até que o Juízo incumbido das Execuções Penais julgue extinto o motivo em que se fundamentara a medida, na forma estabelecida na legislação penal (BRASIL, 1979, s/p).

É necessário considerarmos que a terminologia utilizada no Código de 1979 para se referir ao adolescente autor de ato infracional evidenciava tanto a base para o atendimento destinado a esse público como também a carga ideológica empregada para designar tais sujeitos: a denominada doutrina da situação irregular. Nessa, o adolescente e sua família são culpados, pois seriam eles que não se enquadravam naquilo que era definido como dentro da legalidade, e não a estrutura social organizada como a determinante das circunstâncias que levaram à ilegalidade. Desse modo, responsabilizava-se e punia-se a criança, o adolescente e as famílias pelas condições a que estavam expostos.

\section{Considerações Finais}


Por meio dos estudos realizados podemos compreender que ambos os Códigos eram marcados por uma ideologia constituída por elementos da esfera social que determinavam como destinatários dessa lei todos os que não se enquadravam no modelo social considerado como normal: devia-se proteger a criança para que não se desviasse de um dado padrão e, dessa forma, a ordem social e o progresso da nação estivessem assegurados. Os que haviam sido vítimas de abandono, os órfãos e os que mendigavam pelas ruas passavam a ser objeto dos referidos Códigos.

A denominação e o tratamento dispensados à infância e à adolescência em cada período refletem a organização social, pois, como afirma Bakthin (2004), a produção humana de toda ordem, seja ela relacionada à arte, à literatura, à política, à religião entre outras, tem como base as relações sociais presentes em uma determinada sociedade. A partir dessa mesma organização social, e em consequência dela, também no caso dos termos utilizados para referir-se aos adolescentes autores de atos infracionais, a linguagem exerce e assume uma função social para atingir determinados objetivos.

De tal modo, configura-se a necessidade dos sujeitos enquadrarem-se no que estava estabelecido como normalidade, determinado pelo rigor em relação às regras sociais. Dessa forma, ao utilizar denominações como "menor" e "situação irregular", a linguagem reflete o contexto do tratamento e da visão que se apresentava em relação aos adolescentes em conflito com a lei e à infância pobre.

Pelos antecedentes históricos apresentados até aqui, podemos afirmar que as práticas e as concepções de repressão e de segregação, relativas à infância e à adolescência pobres, de modo geral, foram ocasionadas e ainda o são em decorrência da própria constituição da sociedade de classes. Esta constituição que demanda, principalmente às classes subalternas, um comportamento condizente com a organização do processo de produção.

As políticas sociais, implantadas por meio do Estado, referentes ao público infantojuvenil, mostram-nos que têm estabelecido relação estreita com os interesses do capital, e não com a efetivação de direitos desse segmento; subordinam-se os sujeitos em decorrência da expansão do capital. Ou, no entender de Mészáros, na sociedade capitalista, "[...] tudo o mais, inclusive seres humanos, deve se ajustar, e assim provar sua 'viabilidade produtiva', ou perecer, caso não consiga se adaptar" (MÉSZÁROS, 2003, p. 96).

Contudo, a partir de organizações de movimentos sociais, de grupos de defesa dos direitos da criança e do adolescente, como, também, pela influência de legislações internacionais, são gestadas mudanças no âmbito do atendimento designado à infância e à adolescência no país. Abrangem, inclusive, o atendimento destinado aos adolescentes em conflito com a lei e em privação de liberdade.

Nesse sentido, as décadas finais do século XX, no Brasil, demonstraram um processo de organização dos grupos que estavam à margem, dos movimentos sociais que encadearam as mais variadas lutas, entre elas o reajuste dos salários, melhores condições de moradia, reforma agrária, redemocratização do país, e reivindicaram, também, novas práticas frente às crianças e adolescentes e à instituição de direitos de modo geral. Constituem-se, a partir de então, novas enunciações e procedimentos para o público infanto-juvenil em conflito com a lei, o que não significa que a partir de então esses procedimentos não estejam também subordinados e até mesmo determinados pela manutenção da ordem social estabelecida e não na modificação das condições de vida dos sujeitos.

\section{Referências}


BAKHTIN, Mikhail M. (VOLOCHINOV). Marxismo e Filosofia da Linguagem. São Paulo: Hucitec, 2004.

BRASIL. Código de Menores de 1979. Disponível em: http://www.promenino.org.br. Acesso em: 10 jan. 2015.

Código de Menores de 1927. Disponível em: http://www.promenino.org.br. Acesso em: 15 de jan. 2015.

CARVALHO, Alfredo Roberto de. Inclusão Social e as Pessoas com Deficiência: uma Análise na Perspectiva Crítica. 2009. Dissertação (Mestrado em Educação). Universidade Estadual do Oeste do Paraná - UNIOESTE, Cascavel - PR: 2009.

FALEIROS, Vicente de Paula. Infância e Processo Político no Brasil. In: RIZZINI, Irene; PILlOTTI, Francisco (Orgs.). A Arte de Governar Crianças. A história das Políticas Sociais, da Legislação e da Assistência à Infância no Brasil. 3. ed. São Paulo: Cortez, 2011.

MARCÍLIO, Maria Luiza. História Social da Criança Abandonada. São Paulo: Hucitec, 1989.

MÉSZÁROS, Istvan. O Século XXI: Socialismo ou Barbárie. São Paulo, SP: Boitempo Editorial, 2003.

MIRANDA, Humberto da Silva. Meninos, Moleques, Menores... Faces da Infância no Recife 1927 - 1937. 2008. Dissertação (Mestrado em História Social da Cultura Regional). Universidade Federal Rural de Pernambuco - UFRPE, Recife - PE, 2008.

MOURA, Lia Cruz. Estado Penal e Jovens Encarcerados: uma História de Confinamento. 2005. Dissertação (Mestrado em Ciências Sociais). Pontifícia Universidade Católica de São Paulo - PUC, São Paulo, 2005.

MOTA, Ana Elizabete. Cultura da Crise e Seguridade Social - Um estudo Sobre as Tendências da Previdência e da Assistência Social Brasileira nos Anos 80 e 90. 5. ed. São Paulo: Cortez, 2008.

OLIVEIRA, Salete Magda. A Moral Reformadora e a Prisão de Mentalidades: Adolescentes Sob o Discurso Penalizador. São Paulo: Perspectiva. Vol. 13 nº. 4. 1999. Disponível em: http://www.scielo.br/scielo.php?pid=S010291999000400008\&script=sci_arttext. Acesso em 15 jan. 2015.

PASSETTI, Edson. O Menor no Brasil Republicano. In: PRIORE, Mary Del (org). História da Criança no Brasil. São Paulo: Contexto, 1991. Disponível em: http://pt.scribd.com/doc/47617997/DEL-PRIORE-Mary-Historia-da-Crianca-no-Brasil.

Acesso em: 14 mar. 2015.

RIZZINI, Irene. Crianças e Menores: do Pátrio Poder ao Pátrio Dever. Um Histórico da Legislação para a Infância no Brasil. In: RIZZINI, Irene; PILOTTI, Francisco (Orgs.). A Arte de Governar Crianças: a História das Políticas Sociais, da Legislação e da Assistência à Infância no Brasil. 3. ed. São Paulo: Cortez, 2011.

RIZZINI Irma. A institucionalização de crianças no Brasil: Percurso Histórico e Desafios do Presente. Rio de Janeiro: Editora PUC-Rio; São Paulo: Loyola, 2004.

VIEIRA, Evaldo. A Política e as Bases do Direito Educacional. Campinas: Cadernos Cedes - Políticas Públicas e Educação, $\mathrm{n}^{\mathrm{o}}$. 55, 2001. Disponível em: 
http://www.scielo.br/scielo.php?pid=S010132622001000300001\&script=sci_arttext. Acesso em: 15 dez. 2014.

Estado e Política Social na década de 90. In: NOGUEIRA, F. M. G. (Org.). Estado e Políticas Sociais no Brasil. Cascavel: Edunioeste, 2001.

XAVIER, Maria Elizabete Sampaio Prado. Capitalismo e Escola no Brasil: a Constituição do Liberalismo em Ideologia Educacional e as Reformas do Ensino (19311961). Campinas, SP: Papirus, 1990.

\section{Notas}

${ }^{1}$ Universidade Estadual de Maringá - UEM. Doutoranda em Educação pela Universidade Estadual de Maringá - UEM. Possui graduação em Pedagogia (2005), especialização em História da Educação Brasileira (2008) e mestrado em Educação (2012), todos pela Universidade Estadual do Oeste do Paraná. Atualmente atua como docente colaboradora do curso de Pedagogia da Universidade Estadual do Oeste do Paraná UNIOESTE.

${ }^{2}$ Universidade Estadual de Maringá - UEM. Possui graduação em Pedagogia pela Universidade Estadual de Maringá (1986), mestrado em Educação pela Universidade Metodista de Piracicaba (1992), doutorado em Educação pela Universidade Estadual Paulista Júlio de Mesquita Filho (2000) e pós-doutorado pela Universidade Federal de Santa Catarina (2011). Atualmente é professora associada da Universidade Estadual de Maringá. Tem experiência na área de Educação, com ênfase em Educação Pré-Escolar, atuando principalmente nos seguintes temas: educação infantil, Estado, educação, políticas públicas e políticas educacionais.

${ }^{3}$ Mesmo considerando que a privação de liberdade e o atendimento a este público já era realizada no período colonial, geralmente pela igreja, demarcamos o referido período para início de nosso estudo por ter sido instituída a primeira legislação específica destinada à temática.

${ }^{4}$ Segundo Oliveira (1999), ainda na Primeira República passa-se a utilizar o termo menor. Concebe-se o conceito de menoridade, não apenas vinculado à faixa etária, mas associado à marginalidade, esta considerada tanto nas situações de abandono quanto na prática de delito, ponderando-se que o abandono já era tido como prognóstico de risco crime, constituindo-se o abandono como condição de aptidão para ser objeto de intervenção policial.

${ }^{5}$ Por meio desta lei se institui também, artigo 146, o Juizado de Menores; 'É creado no Districto Federal um Juizo de Menores, para assistencia, protecção, defesa, processo e julgamento dos menores abandonados e delinquentes, que tenham menos de 18 annos' (BRASIL, 1927, s/p).

${ }^{6}$ Este Código continha 231 artigos e foi assim chamado para homenagear o seu autor, o jurista José Cândido de Albuquerque Mello Mattos, primeiro juiz de menores do país (MIRANDA, 2008).

${ }^{7} \mathrm{O}$ artigo 26 do referido Código de Menores estabelece quem seriam os menores de 18 anos que poderiam ser considerados como abandonados. Disponível em: http://www.promenino.org.br. Acesso em: 20 set. 2014.

${ }^{8}$ Essas três categorias de designação as crianças e adolescentes que poderiam ser apreendidas e internadas estavam assim descritas: 'Art. 28. São vadios os menores; Art. 29. São mendigos os menores que habitualmente pedem esmola para si ou para outrem; Art. 30. São libertinos os menores que habitualmente: a) na via publica perseguem ou convidam companheiros ou transeuntes para a pratica de actos obscenos; b) se entregam á prostituição em seu proprio domicilio, ou vivem em casa de prostituta, ou frequentam casa de tolerancia, para praticar actos obscenos; c) forem encontrados em qualquer casa, ou logar não destinado á prostituição, praticando actos obscenos com outrem; d) vivem da prostituição de outrem' (BRASIL, 1927, $\mathrm{s} / \mathrm{p})$.

${ }^{9}$ Apesar de o artigo 101 estabelecer: 'é prohibido em todo o territorio da Republica o trabalho nos menores de 12 annos'. O artigo 102 proibia o trabalho a menores de 14 anos no caso destes não terem completado a instrução primária, mas abria exceção para os casos em que o trabalho do adolescente fosse indispensável para subsistência, Conforme exposto no Código: 'Igualmente não se póde ocupar a maiores dessa idade que 
contem menos de 14 annos. e que não tenham completando sua instrucção primaria. Todavia. a autoridade competente poderá autorizar o trabalho destes, quando o considere indispensavel para a subsistencia dos mesmos ou de seus paes ou irmãos, comtanto que recebam a instrucção escolar, que lhes seja possível' (BRASIL, 1927, s/p).

${ }^{10}$ A característica fundamental do período denominado como 'Estado de Bem Estar Social' '[...] é o papel desempenhado pelos fundos públicos no financiamento da reprodução da força de trabalho e do próprio capital [...]' (MOTA, 2008, p. 128). De acordo com Vieira (2001), esta fase '[...] representou uma criação do capitalismo, foi possível em determinado momento do capitalismo, surgindo, sobretudo, nos países onde o crescimento no pós II Guerra Mundial (1945) foi muito acentuado. Não existiu Estado de Bem Estar Social fora desses países e ele começou a morrer com a crise a partir da década de 70' (In: NOGUEIRA, p. 20). Deste modo, teóricos como Evaldo Vieira (2001-1983), Ana Elizabete Mota (2008), José Luís Fiori (1997), entre outros, questionam e negam a existência do período chamado de 'Bem Estar Social' no Brasil.

${ }^{11}$ A princípio, quando de sua instituição, o SAM atuava somente no Distrito Federal, contudo, a partir do decreto-lei nº 6.865 de 1944, o órgão passou a ter caráter de atuação nacional.

12 O estabelecimento dessa "ordem consentida" camufla uma aceitação da população frente ao poder instituído, na maioria das vezes, por meio da força ou por meio de políticas sociais mínimas. Aqui os exemplos paradigmáticos são o FGTS e a unificação dos institutos de aposentadoria e pensões no INPS, ambos em 1966 (MOTA, 2008, p. 137).

13 A referida doutrina pode ser definida como aquela em que os menores passam a ser objetos da norma, ou seja, quando não se ajustam ao padrão estabelecido. A declaração de situação irregular tanto pode advir de sua conduta pessoal (caso de infrações praticadas pelo menor ou de desvio de conduta), como da família ou da própria sociedade.

13Artigo - $1^{\mathrm{o}}$ 'Este Código dispõe sobre assistência, proteção e vigilância a menores: I - até dezoito anos de idade, que se encontrem em situação irregular; II - entre dezoito e vinte e um anos, nos casos expressos em lei’ (BRASIL, 1979, s/p).

14 Artigo - $1^{\text {o }}$ Este Código dispõe sobre assistência, proteção e vigilância a menores: I - até dezoito anos de idade, que se encontrem em situação irregular; II - entre dezoito e vinte e um anos, nos casos expressos em lei' (BRASIL, 1979, s/p).

Recebido: julho-15 Aprovado: fevereiro-16 